\title{
Promising indications in the journey of the Mental Health Pathway collaboration between police and health in Scotland
}

\author{
Claire E. Coleman*
}

This article is related directly to the $6^{\text {th }}$ International Law Enforcement $\mathcal{E}$ Public Health (LEPH) Virtual Conference in March 2021.

\begin{abstract}
Mental Health Pathway is a pioneering collaborative project in Scotland between police and health professionals seeking to get the first point of contact right for the public in relation to their mental health. Six months after the launch of the first stage, we take a reflective look over what has taken place and look to the future plans.
\end{abstract}

Mental Health Pathway (MHP) is a new collaborative project between NHS24, Ambulance (SAS - Scottish Ambulance Service), and Police Scotland, its key objective being to better support the public in Scotland in relation to mental health Right Care, Right Time.

Prior to the Pathway, the police and ambulance service traditionally took a person in mental health crisis to an Accident \& Emergency department for assessment. This approach has been found to be both embarrassing for the person in crisis and frustrating for the officers as they knew this was the wrong journey for the person (Figure 1). This photograph from October 2018, courtesy of BBC News (https://www.bbc. co.uk/news/uk-scotland-47141260) shows the extent of a typical night at a Scottish hospital, where its car park is filled with police vehicles. Within a rural setting, the officers may have

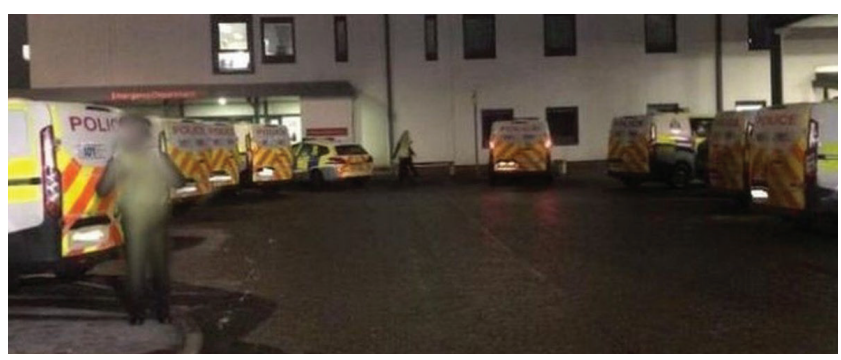

FIGURE 1 Larbert Hospital car park October 2018 had to travel excessive distance and/or use ferries to leave Islands to enable the person to receive support.

Figure 2 shows the Pathway timeline from conception in 2017 to August 2020, charting its various achievements and milestones. One of the first objectives of the group was to truly understand the roles and responsibilities of the police and ambulance services. Additionally, when opportunities presented, they engaged in joint learning, including live listening in exercises and attending training together, which consolidated the small group.

In 2019, NHS24 launched their Mental Health Hub (MHH) for any person within Scotland, regardless of age, to be able to access mental health support by telephone. Initially it was open just four nights a week; however, due to its success and demand, the service rapidly increased to $24 / 7$.

When contacting the Hub, the first person a member of the public speaks to is a Psychological Wellbeing Practitioner (PWP). This non-clinician role is unique to the Hub, with practitioners who have excellent life skills and are specifically trained to support people in distress. Most people who phone the Hub are supported by a PWP to safe self-care. The Hub is also staffed by Mental Health Nurse Practitioners and Mental Health Senior Charge Nurses. If needed, they will supervise the call to a safe outcome.

In addition, the staff can also offer other services, such as the National Distress Brief Intervention Service, where local health partners can support the person for a few days. Some people are directed to a primary care out-of-hours service,

Correspondence to: Claire Coleman, c/o Police Scotland, Tulliallan Castle, Tulliallan, Alloa Clackmannanshire FK10 4BE, United Kingdom. E-mail: claire.coleman@scotland. pnn.police.uk.

To cite: Coleman, C. E. (2021). Promising Indications in the Journey of the Mental Health Pathway Collaboration Between Police and Health in Scotland. Journal of Community Safety and Well-Being, 6(2), 80-82. https://doi.org/10.35502/jcswb.203

@ Author(s) 2021. Open Access. This work is distributed under the Creative Commons BY-NC-ND license. For commercial re-use, please contact sales@sgpublishing.ca. SgPUBLISHING Published by SG Publishing Inc. CSKA Official publication of the Community Safety Knowledge Alliance. 


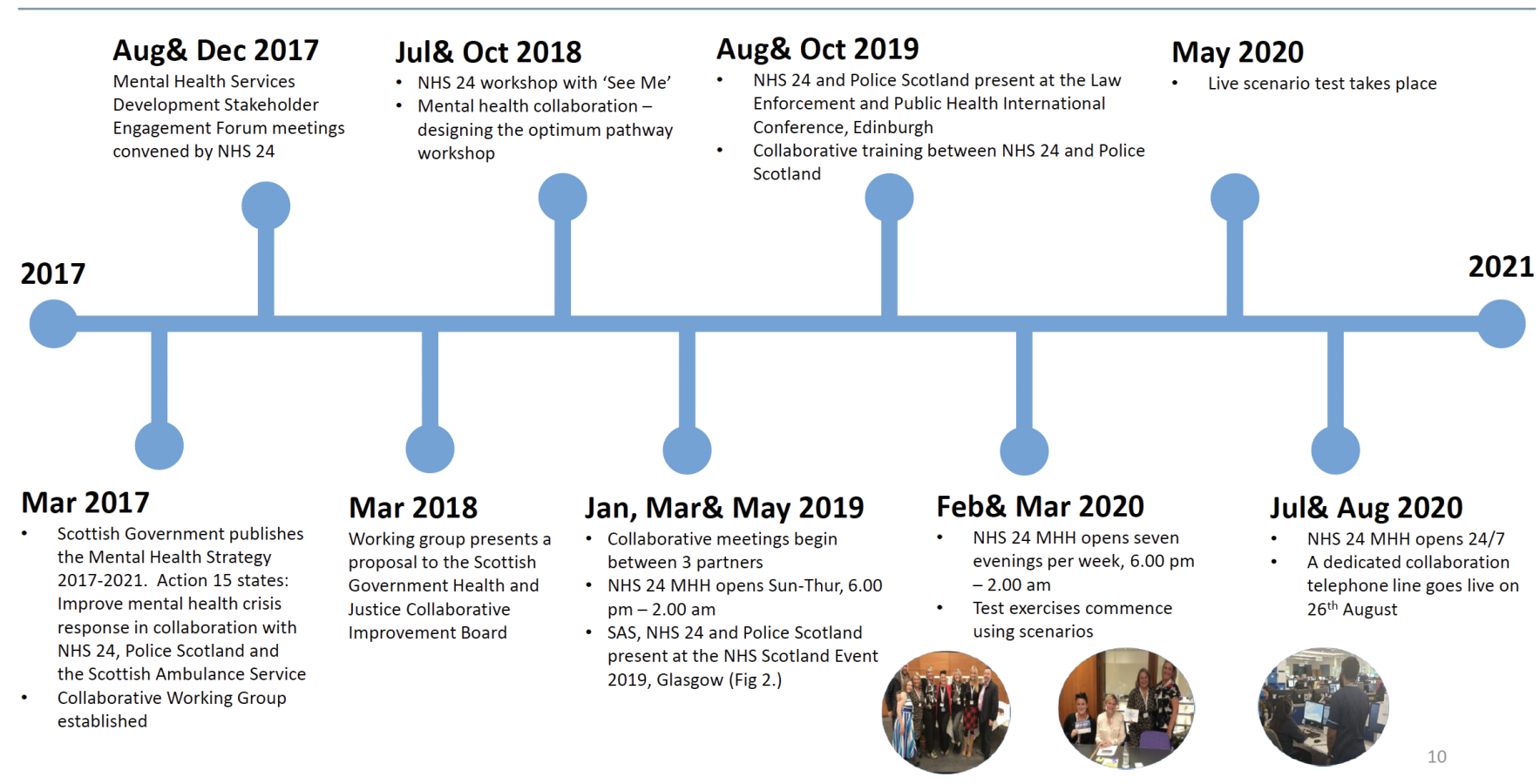

FIGURE 2 MHP Timeline

and very few people are referred to a local accident and emergency department, or emergency services. The most common reasons for contacting the Hub include suicide, anxiety, low mood, psychosis, and self-harm.

Over the summer of 2020, over 600 Police Service Centre Advisors (civilian role and initial point of contact with Police Scotland either by telephone or email) completed a bespoke learning program designed in collaboration with NHS24 and Edinburgh Napier University. One concern for the police side of the collaboration was officers and staff letting go of the incident and passing the responsibility to another service. To achieve buy-in, the project team provided an extensive engagement and learning program, which received $97 \%$ positive feedback. This program allowed them to effectively assess public contact for mental health and distress, and if it fit the Mental Health Hub referral criteria, they would complete the referral with the consent of the member of the public.

The MHH referral criteria are as follows:

Any public contact where it appears that an ADULT (any person aged 16 years or older) would benefit from Mental Health support and where there is NO:

\section{IMMEDIATE threat to life}

reason for police involvement, beyond an apparent need for health/mental wellbeing support.

In short, through this referral system, a member of the public speaks with a PWP within 10 minutes, no officers are deployed, and the support remains with the Mental Health Hub team.

Since the launch at the end of August 2020, MHH referrals have grown in strength and maturity to over 1,300 referrals, with staff describing this introduction as providing them the opportunity to "listen to the callers and assess their needs more efficiently, knowing that we now have an appropriate resolution for them."

In December 2020, the ability to make such referrals was rolled out to the rest of the Police Scotland Contact, Communications and Command division, which includes Police Control rooms. The last stage of the $\mathrm{MHH}$ referrals will be introducing the ability to make referrals to the rest of Police Scotland, from the uniformed officer in Dumfries, to the Station Assistant in Benbecula, to the Detective noting a historical abuse statement in Edinburgh.

Six months after the launch of the referrals, a joint evaluation is currently taking place between NHS24 and Police Scotland, which will be published in spring 2021. Early indications have shown that there is a fair split between genders, 53\% male and $47 \%$ female, in people who use the Hub. Ages range from 16 to 89 years (although the Hub is available for any age, Police Scotland only refer 16 years and above), with the most prevalent age range being 50 to 59 years, at 19\% (Figure 3).

Of interest, $32 \%$ of referrals are made during core opening times (0900 to $1700 \mathrm{hrs}$ ) for General Practitioners and local mental health support services, and the most popular time is 23:00 to $23: 59$ hrs, with $12 \%$ of referrals. Saturdays are busiest (17\%), followed closely by Sunday and Tuesday (15\%), and the least busy is Monday with $11 \%$ (Figure 4).

It was also established that people contacted the police looking for mental health support after their own dealings with the police due to criminality, which includes both victims and accused. From April 2020, all persons being released from police custody will be provided with written information regarding the Hub. It is hoped that with the national rollout across the rest of Police Scotland, this service will better support victims when sign-posting can be conducted during all police dealings. 


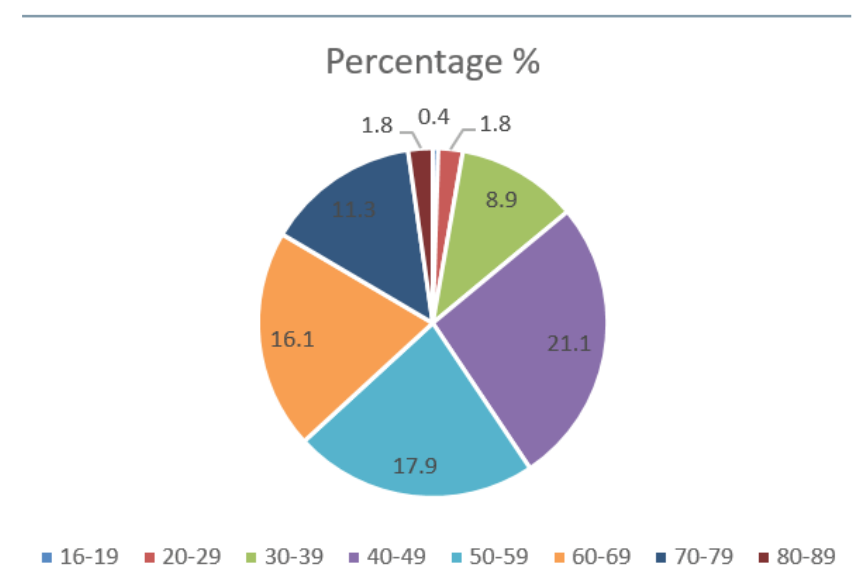

FIGURE 3 Ages of people referred to the Hub

The most popular reason identified for referring to the Hub is feelings of low mood and depression, with $49 \%$ and $17 \%$, respectively, stating they had suicidal feelings but could keep themselves safe long enough for Hub contact. What is key out of all the findings is that $93 \%$ of referrals resulted in a non-emergency intervention combining the following:

- self-care, such as mindfulness, identifying coping strategies or grounding techniques

- General Practitioner (GP) post-contact

- Distress Brief Intervention (24-hr post-follow-up support)

As Police Scotland moves to phase 2, the introduction of Mental Health Nurse Practitioners into Police Control rooms, in the summer 2021, the Pathway members have been in conversation with their colleagues in England and Wales, where there are many examples of such work, and in some case for over eight years, such as at the Leicestershire Constabulary. This has allowed for sharing of information and identification of best practices.

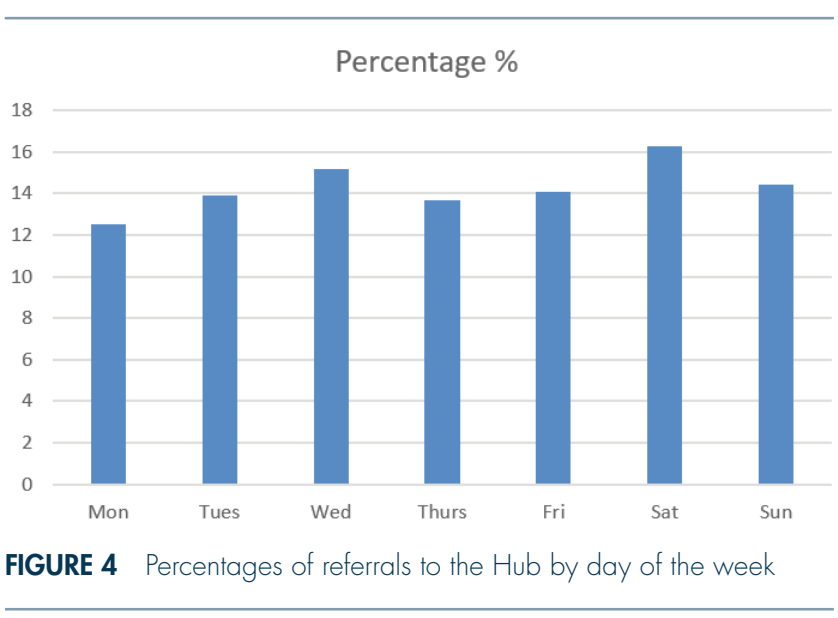

Those who have benefitted the most from the Pathway have been the officers and staff within Police Scotland, who all speak highly of the collaboration and have fully embraced it. Early indications point to the potential for greater benefits for the health care system and general safety and well-being of persons affected by mental health conditions.

If you wish to find out more about the Mental Health Pathway, please contact claire.coleman@scotland.pnn.police.uk

\section{ACKNOWLEDGEMENTS}

The author would like to acknowledge Tracy Ward, Police Scotland, for support in data collection, and Dan Harley, NHS24, for the Figure 2 Timeline.

\section{CONFLICT OF INTEREST DISCLOSURES}

The author has no conflicts of interest to declare.

\section{AUTHOR AFFILIATIONS}

*Police Officer, Mental Health Pathway project, Police Scotland Scotland 